\title{
Enhanced Analytical Hierarchy Process for U-Learning with Near Field Communication (NFC) Technology
}

\author{
Huzaifa Marina Osman ${ }^{1}$, Manmeet Mahinderjit Singh ${ }^{2}$, \\ Azizul Rahman Mohd Shariff ${ }^{4}$, Anizah Abu Bakar ${ }^{5}$ \\ School of Computer Sciences, University of Science \\ Malaysia, Penang, \\ Malaysia
}

\begin{abstract}
Integration of current Virtual Learning Environment (VLE) system with the Near Field Communication (NFC) technology provides Ubiquitous Learning Environment (ULE) in education. The utilization of NFC technology in ULearning concept will help to improve accessibility and encourage collaborative learning methods in the education sector. In this paper, we conduct a study to investigate eleven (11) adoptions factors of U-Learning with NFC and ranking them using Analytical Hierarchy Process (AHP) a multicriteria decision-making (MCDM) approach. We also utilized Technology Acceptance Model (TAM), Technology Readiness (TR), and combination of TAM and TR (TRAM) as theoretical framework. We have identified TRAM as the best tool based on literature review and utilized the theory to propose an NFCEnabled Ubiquitous Technology model. The model was utilized to design a questionnaire for survey about user acceptance. Results from the online survey were analyzed using AHP in an absolute measurement approach method. Results from AHP show that optimism is the most influencing factor in adoption of U-Learning using NFC technology followed by innovativeness and accessibility. Finally, this paper contributes in designing an NFC research model.
\end{abstract}

Keywords-Ubiquitous learning (U-Learning); virtual learning; multi criteria decision making (MCDM); Analytical Hierarchy Process (AHP)

\section{INTRODUCTION}

The emergence of wireless and sensor-based technology such as Near Field Communication (NFC) offers great potential to be utilized in education system. The NFC technology provides advantages in the context of teaching and learning it allows a better condition in the data exchange process [1].

Integration of current Virtual Learning Environment (VLE) system with the NFC technology provides Ubiquitous Learning Environment (ULE) in education. Both NFC technology and U-Learning are ubiquitous and pervasive concept, which is interconnected with each other. The utilization of NFC technology in U-Learning concept will help to improve accessibility and encourage collaborative learning methods in the education sector [2]. Besides, this utilization will give valuable benefits for education because it could offer

\author{
Manuel Serafin Plasencia ${ }^{3}$ \\ Universidad Nacional Experimental Politechnica \\ Bolivar, \\ Venezuela
}

an active learning and enhance interaction between students and teachers.

The need of innovation and new approaches are essential in education in order to increase quality of education [3]. There are challenges in current teaching and learning technologies such as: accessibility issues in current VLE system, low student motivation, as well as lack of ICT equipment with current VLE approach.

We proposed three research questions in order to achieve the objectives of the study: i) what is user's acceptance about U-Learning using NFC technology in education?; ii) What are the factors that most impacts the adoption of U-Learning using NFC technology?; iii) What are the applications of ULearning using NFC technology for education? In consequence three objectives have been identified: i) to study the user acceptance towards the usage of Ubiquitous Learning with NFC technology in education; ii) to rank adoption factors of U-Learning using NFC technology in education using AHP methods in MCDM and iii) to propose a framework for ULearning using NFC technology applications in education. The outline of the paper is as the following. Section II demonstrates the state of art. Section III and IV present the research methodology and proposed work respectively. Section V and VI focus on the discussions, findings and conclusion.

\section{LITERATURE REVIEW}

\section{A. Factors in Influencing usage of U-Learning}

Six characteristics of U-Learning influences its usage for education: mobility of learning environment, urgency of learning requirements, situating of instructional task, interaction in the learning process, initiative in obtaining knowledge, and combination of instructional content [4]. In contrast, three characteristics of U-Learning that influenced its use was identified: accessibility, immediacy and permanency [5]). However, [6] have combined these characteristics with interactivity and situating of instructional tasks that was proposed by [4] as U-Learning characteristics.

The factors that lead users to use U-Learning are whose provides users with the characteristics of context-awareness, seamless services as well as adaptive services [7]. It is a 
concept of pervasive and omnipresent whereby it allows content or information to be accessed in the right context [7]. It is clearly demonstrated that the characteristic of U-Learning which is 'anywhere' and 'any time' influenced others to use ULearning. However, [8] indicate as characteristics of ULearning: accessibility, immediacy, interactivity, contextawareness and permanency.

Another factor is the integration of wireless technology with web technology and the use of Internet sources that enable users to obtain information according their free time and from where [9], [10]. Previous studies showed that characteristic of mobile device [11] and ease of use are also factors that influenced utilization and usage of U-Learning. [4] and [5] also proposed immediacy, interactivity, accessibility, permanency and situating instructional activities as major characteristics of U-Learning. Accordingly, in this research five characteristics of U-Learning as influencing factors of ULearning usage was proposed based on the similarities in literature findings.

\section{B. Multi Criteria Decision Making (MCDM)}

MCDM refers to a process of decision making with the presence of multiple criteria, which are usually conflicting [12]. Analytic Hierarchy Process (AHP) proposed by [13], [14], [15], is a MCDM effective tool. AHP breaks down complicated MCDM problem by means of a hierarchy to elicit pairwise comparisons judgments that facilitates the evaluation [16], [17]. The judgments are arranged in a pairwise comparison matrix and priorities are derived from its main eigenvector enabling to compare and rank the alternatives. A consistency index is estimated to check transitive consistency of the derived priorities. This method is simple, systematic, dependable, and user friendly and several suitable software options are available to decision makers [18]. According to [19] there are four main steps in AHP process: define problem; formulate hierarchy structure consisting of a goal, criteria and alternatives; elicit pairwise comparisons; and utilize priorities based on comparisons.

\section{Middleware for Internet of Things (IoT)}

Middleware that need to be considered in IoT with utilization NFC technology is Open NFC because it is appropriate and compatible with any other NFC compliant. Any NFC applications developed using Open NFC middleware is applicable and appropriate to be utilized by any smartphone brands [20]. Open NFC is used as middleware to connect the Network Layer and Application Layer in the architecture of IoT. The research presented Open NFC architecture to propose a framework for NFC application.

Mobile RFID-Enabled Android (MORENA) is the model of the Google Android NFC API. It is the most progressive NFC API for smart devices available in the market. MORENA is modeled to grant the developer to execute applications for NFC-enabled devices without dealing with hardware details [21]. MORENA minimize the complexness in designing an application for RFID-enabled Android devices. In contrast to utilize the Android NFC API in which provides better experience for users, ambient-oriented programming is considered as an alternative for distributed computing, which allows MORENA to distribute spaces [21]. The abstraction provides MORENA with ability to create applications for RFID-enabled Android in five various ways: asynchronous interaction, tracking via connectivity, allows support of beam, First-Class References for IoT objects, and unpaired in time.

\section{User Acceptance Models}

The user acceptance models discussed in this research are Technology Acceptance Model (TAM) and Technology Readiness (TR). TAM is a model that defined the use of technology and technology acceptance [22]. TAM emerged from the Theory of Reasoned Action [23] with the purpose to provide a better explanation about computer acceptance and the user's attitude about computing technologies [24]. TAM was introduced by [24]. It has two key attributes which are Perceived Ease of Use (PEOU) and Perceived Usefulness (PU). TAM is a theoretical model that helps in explaining and predicting user's behavior towards IT [25]. Davis insisted that PU can best described as key variables that convinced people to utilize a particular system or application which can enhance their work proficiency [24], [26]. TAM has analytically proved in distinctive research studies in diverse contexts [27].

TR model is developed by [28] to describe the user's tendency to accept and use recent technologies to complete their task. TR construct can be described as states of mind as it is closely related with an overall variables and obstacles which resulted in how people's tendency in facilitating new technology [28], and includes four aspects: inconvenient, innovative, insecurity, and optimism. From TR, the Technology Readiness Index (TRI) was developed as an appropriate tool to identify early technology users. TRI is a condition of mind refined from understanding of mental enablers as well as inhibitors of user's willingness regarding current technologies [29].

\section{RESEARCH METHODOLOGY}

This research was accomplished by phases. Phase 1: designing a taxonomy of five categories (NFC versus RFID, NFC operation modes, ISO standards, NFC applications, and user acceptance model) for reviewing NFC technology and user acceptance model literature. A website to give basic information about the NFC technology and its implementation in U-Learning was developed. A video presentation about ULearning with NFC technology was produced and uploaded to the website. A questionnaire was designed and uploaded on a free online survey platform. The questionnaire was prepared based on TR model, TAM model, and some Technology Characteristics, which emerges as TRAM model, the approach currently being implemented [30]. The TRAM model is utilized to propose a model for NFC-enabled Ubiquitous Technology characteristics. Components of NFC-enabled Ubiquitous Technology suitable and appropriate with characteristics of U-Learning using NFC technology were identified by means of a literature review.

Based on the analysis of adopting factors of sensor-based technology such as NFC technology, utilized in current educational technology such as U-Learning, it is essential for individuals to trust in U-Learning using NFC technology will improve teaching and learning in term of quality and 
efficiency, which is considered as PU. Besides, it allows users to complete their task in right time, which refer to PEOU.

TR model is also appropriate because it is capable to evaluate current technology such as NFC technology because of it constructs appropriateness (innovativeness, optimism, discomfort, and insecurity). Components of NFC-Enabled Ubiquitous Technology Characteristics were adopted because its potential effect on PU. The integration of TAM, TR and proposed NFC-Enabled Ubiquitous Technology Characteristics is considered as a TRAM model, and it is adopted in this research.

Twenty-two (22) questions were laid in two sections survey questionnaire: Demographic Section (8 questions) and Adoption Factors of U-Learning using NFC Technology Section (14 questions associated to any of three constructs taken from the TAM model). Table I display all the determinants used in designing the survey questions. All the questions were designed as multiple choice with a Likert-type scale. The scores ranged from: 1 - Strongly Disagree to $5-$ Strongly Agree. The survey questionnaire was designed using KwikSurveys (an online free platform). The online survey was conducted within four weeks' time span and its weblink was distributed via e-mail, word-of-mouth and WhatsApp

TABLE I. DETERMINANTS IN SURVEY QUESTIONNAIRE

\begin{tabular}{|l|l|}
\hline Determinant & Item number \\
\hline Age & 1 \\
\hline Gender & 2 \\
\hline Level of Education & 3 \\
\hline Status & 4 \\
\hline Having smartphone & 5 \\
\hline Knowledge about sensor-based technology & $6-8$ \\
\hline Innovativeness & 9 \\
\hline Optimism & 10 \\
\hline Discomfort & 11 \\
\hline Insecurity & 12 \\
\hline Responsiveness & 13 \\
\hline Smartness & 14 \\
\hline Permanency & 15 \\
\hline Accessibility & 16 \\
\hline Immediacy & 17 \\
\hline Interactivity & 18 \\
\hline Context-awareness & 19 \\
\hline Ease of Use & 20 \\
\hline Usefulness & 22 \\
\hline Intention to Adopt & 21 \\
\hline
\end{tabular}
website was developed using a free platform. The intention of the NFC website has provided the fundamental information about the NFC technology such as operation modes of NFC, differentiation between NFC and RFID and basic information about U-Learning. A video presentation about U-Learning with NFC technology was also included on the website. The website also contains link to the survey questionnaire providing direct access to the respondents once they accessed the website.

The video was created using free video application software. The video focused on issues regarding teaching and learning, the comparison of teaching and learning for teachers and students with and without technology utilization, and how the NFC technology brings great potential, which can overcome existing issues in teaching and learning. The video highlighted the effectiveness of U-Learning using NFC technology.

A pretesting session of the survey was executed. The purpose of pretesting questionnaire was to identify either respondents really comprehend with the concept, terminology and words used in the survey. In the pretest session a brief explanation of the research model was given at the beginning. The outcomes enabled the research team to amend the questionnaire and website by means of analyzing the pretesting session participant's feedback. Based on the participant's feedback new technical terminology, clearer statement of the complicated questions, and simplified instructions was provided.

Target populations in this research are teachers and students in education institutions. The non-random sample was defined by means of respondent self-selection during the time frame. The final sample size was of 125 respondents. The data collected was analyzed using SPSS based on the selected research model and hypothesis.

In phase 2, the data collection from the online survey was processed to become the input to MCDM using AHP in a very new approach. The outcome was an importance ranking of the adoption factors identified in the literature and included in the model towards the idea of U-Learning using NFC technology. This ranking is derived from the synthetized weights obtained from the survey respondents by means of an absolute measurement approach in AHP. In phase 3, a simple framework for U-Learning using NFC technology application was designed using the research generated knowledge.

\section{A. Sample Description}

The observation on the two determinants in demographic section indicates that respondents are mostly females and are having smartphone as listed in Table II.

Results from determinant of respondents' point of view about sensor-based technology from survey questionnaire indicate that most respondents have some knowledge about sensor-based technology as listed in Table III. The percentage of respondents aware about sensor-based technology is $50.4 \%$ and respondents that only heard about sensor-based technology is merely $3.2 \%$. 
TABLE II. DEMOGRAPHIC PROFILE OF RESPONDENT

\begin{tabular}{|l|l|c|l|}
\hline Variables & Categories & Frequencies & Percentage (\%) \\
\hline \multirow{4}{*}{ Gender } & Male & 58 & 46.4 \\
\cline { 2 - 4 } & Female & 67 & 53.6 \\
\cline { 2 - 4 } & Total & $\mathbf{1 2 5}$ & $\mathbf{1 0 0}$ \\
\hline \multirow{3}{*}{$\begin{array}{l}\text { Having } \\
\text { smartphone }\end{array}$} & Yes & 125 & 100 \\
\cline { 2 - 4 } & No & 0 & 0 \\
\cline { 2 - 4 } & Total & $\mathbf{1 2 5}$ & $\mathbf{1 0 0}$ \\
\hline
\end{tabular}

TABLE III. QUESTION ON RESPONDENTS’ POINT OF VIEW ABOUT SENSORBASED TECHNOLOGY

\begin{tabular}{|l|l|l|}
\hline Categories & Frequencies & Percentage (\%) \\
\hline I did not know about it at all. & 1 & 0.8 \\
\hline I have only heard about it. & 4 & 3.2 \\
\hline $\begin{array}{l}\text { I am aware with the sensor- } \\
\text { based technology }\end{array}$ & 63 & 50.4 \\
\hline $\begin{array}{l}\text { I have some knowledge of what } \\
\text { it is. }\end{array}$ & 55 & 44.0 \\
\hline $\begin{array}{l}\text { I know all about sensor-based } \\
\text { technology. }\end{array}$ & 2 & 1.6 \\
\hline
\end{tabular}

Table IV indicates how long respondents know about sensor-based technology. The highest percentage of how long respondents know about sensor-based technology is within 6 months to 1 year with $44 \%$, followed by $27.2 \%$ of respondents know for 1 to 2 years, $16.8 \%$ know for 2 to 3 years and $9.6 \%$ of respondents know for less than 6 months. Only $2.4 \%$ of respondents know about sensor-based technology for more than 3 years.

TABLE IV. QUESTION ON HOW LONG RESPONDENTS KNOW ABOUT SENSOR-BASED TECHNOLOGY

\begin{tabular}{|l|l|l|}
\hline Categories & Frequencies & Percentage (\%) \\
\hline Less than 6 months & 12 & 9.6 \\
\hline 6 months to 1 year & 55 & 44.0 \\
\hline 1 year to 2 years & 34 & 27.2 \\
\hline 2 years to 3 years & 21 & 16.8 \\
\hline Over 3 years & 3 & 2.4 \\
\hline
\end{tabular}

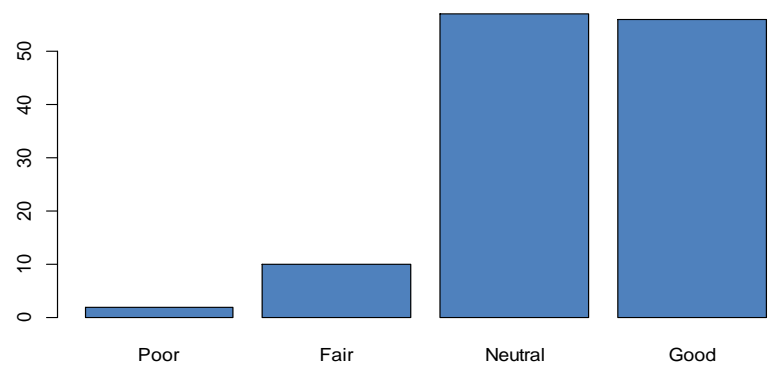

Fig. 1. Survey Respondents' Knowledge about Sensor-based Technology.
The following question examined how respondents rate their knowledge about sensor-based technology in a qualitative scale consisted of: (1) Poor, (2) Fair, (3) Neutral, (4) Good and (5) Excellent. None respondent judges their knowledge as excellent and $45.6 \%$ of respondents answered Neutral. Fig.1 shows the responses spread.

\section{RESULTS}

All data gathered from survey linked with a research model for Adoption Factors of U-Learning using NFC Technology showed in Fig.2. There are fourteen (14) determinants in the model of Fig.2. For each one of them three (3) items were presented to the respondents in the survey (adding up to 42 items). The respondents could choose one of five categories of agreement (Strongly Disagree, Disagree, Neutral, Agree, or Strongly Agree). Then, each question is a bipolar attribute to express a belief including neutral or zero degree of belief [31]. The answer choices were coded to suitable represent the expressed belief and for further processing as shows in Table V.

TABLE V. CODing VALUe to InTERPREt Answer Choice

\begin{tabular}{|l|l|}
\hline Answer Choice & Value \\
\hline Strongly Disagree & -3 \\
\hline Disagree & -1 \\
\hline Neutral & 0 \\
\hline Agree & 1 \\
\hline Strongly Agree & 3 \\
\hline
\end{tabular}

Technology Readiness

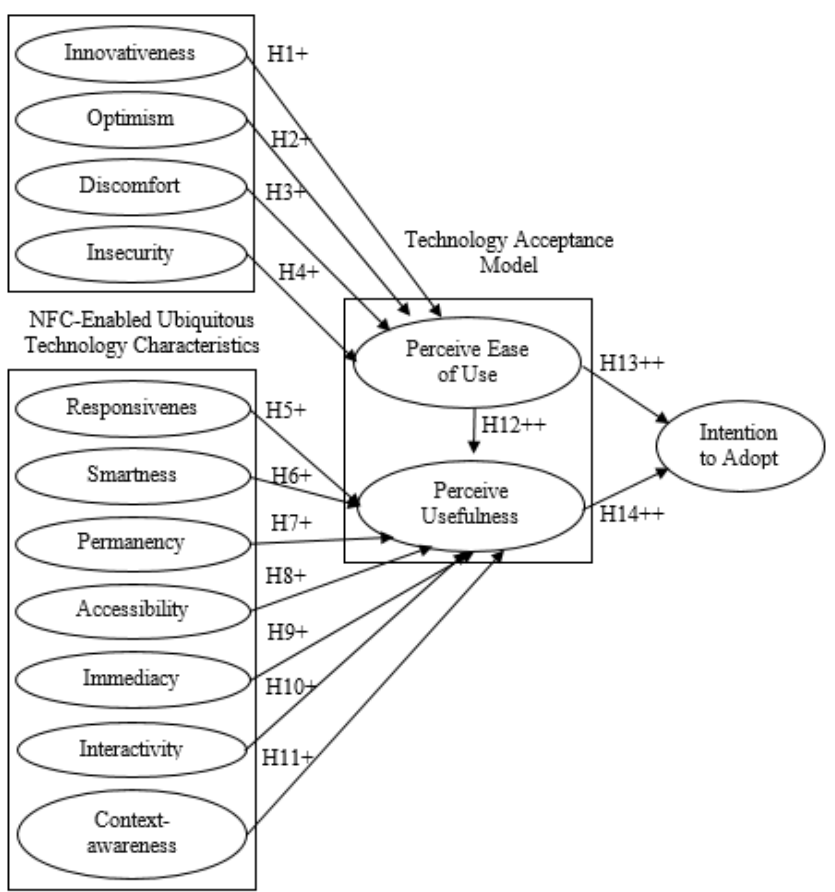

Fig. 2. Model of Research Study. 


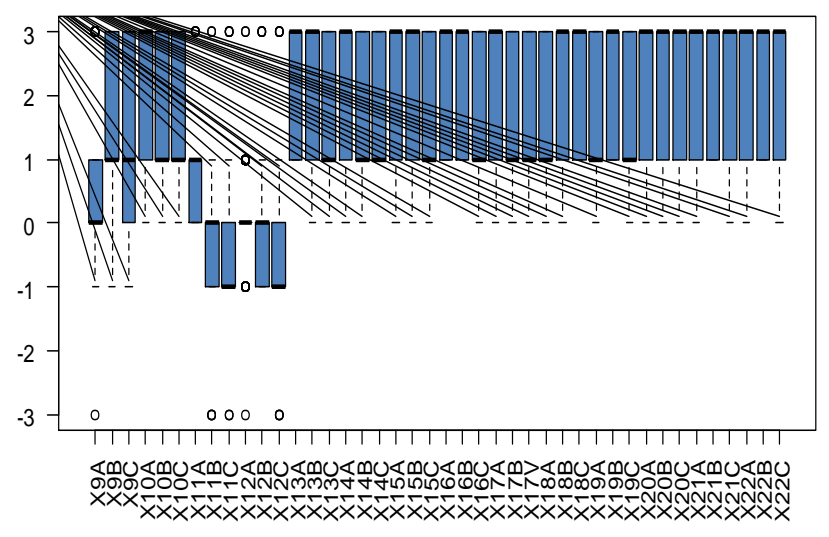

Fig. 3. Boxplot of Answers to Research Model Items.

Fig.3 summarizes the answers of the 42 items showing a high concentration of agreement. Exceptions are showed in items 11 and 12, both in parts B and C. The circles in fig. 3 depict outliers in items 9 part A, 11 parts A, B and C, and 12 parts $\mathrm{A}, \mathrm{B}$ and $\mathrm{C}$. The most intriguing item is 12 part $\mathrm{A}$ where the respondent judged risk regarding use of wireless devices in contrast with wired ones, the modal answer for this item was neutral (89 of $125-71.4 \%$ ) than any other answer is atypical.

\section{A. Multi Criteria Decision Making}

Results from the online survey were utilized in the MCDM process with AHP approach. AHP is a theory of relative measurement able to deal with intangible criteria [32]. The ultimate scope of the AHP is that of using pairwise comparisons between alternatives as inputs, to produce a rating of alternatives, compatibly with the theory of relative measurement [33]. When using relative measurement, the interest is on the proportions between some quantities instead of the exact measurement of them, but from the very beginning [34] attend to absolute and relative measurement as well. The absolute measurement in AHP is called the rating mode [19].

AHP is a method for building an evaluation model with the following main characteristics: (1) evaluation model is structured in a hierarchical way; (2) same assessment technique is used at each node of the hierarchy; (3) assessment of the sub nodes of a common node is based on pairwise comparisons. It works with a minimum of three levels, the top of the hierarchy represented by the goal, in this case it is Intention to Adopt. It is the parent node of the criteria level that presents in this research two elements: PEOU and PU. Finally, the alternative level disclosed four sub nodes under PEOU (Innovativeness, Optimism, Discomfort, and Insecurity) and other seven children nodes to PU (Responsiveness, Smartness, Permanency, Accessibility, Immediacy, Interactivity, and Context-awareness). Each node implies a decision matrix of order nxn where $n$ is the number of sub nodes. There are three matrices one for the goal node ( $2 \times 2$ dimension) and one for each node at the criteria level, at the PEOU node is an order 4 matrix (4x4 dimension), and an order 7 matrix ( $7 \times 7$ dimension) linked to PU node.
TABLE VI. SCALE VALUES FOR EXPERT JUdGMENT ON PROPOSED MODEL ELEMENTS

\begin{tabular}{|c|c|}
\hline Combinations of Item's Answers & Value \\
\hline 3 Strongly Disagree & -9 \\
\hline 2 Strongly Disagree \& 1 Disagree & -7 \\
\hline 2 Strongly Disagree \& 1 Neutral & -6 \\
\hline 2 Disagree \& 1 Strongly Disagree & -5 \\
\hline 2 Strongly Disagree \& 1 Agree & -5 \\
\hline 1 Strongly Disagree \& 1 Disagree \& 1 Neutral & -4 \\
\hline 1 Strongly Disagree \& 1 Disagree \& 1 Agree & -3 \\
\hline 2 Neutral \& 1 Strongly Disagree & -3 \\
\hline 2 Strongly Disagree \& 1 Strongly Agree & -3 \\
\hline 3 Disagree & -3 \\
\hline 1 Strongly Disagree \& 1 Neutral \& 1 Agree & -2 \\
\hline 2 Disagree \& 1 Neutral & -2 \\
\hline 1 Strongly Disagree \& 1 Disagree \& 1 Strongly Agree & -1 \\
\hline 2 Agree \& 1 Strongly Disagree & -1 \\
\hline 2 Disagree \& 1 Agree & -1 \\
\hline 2 Neutral \& 1 Disagree & -1 \\
\hline 1 Neutral \& 1 Disagree \& 1 Agree & 0 \\
\hline 1 Neutral \& 1 Strongly Disagree \& 1 Strongly Agree & 0 \\
\hline 3 Neutral & 0 \\
\hline 1 Strongly Disagree \& 1 Agree \& 1 Strongly Agree & 1 \\
\hline 2 Agree \& 1 Disagree & 1 \\
\hline 2 Disagree \& 1 Strongly Agree & 1 \\
\hline 2 Neutral \& 1 Agree & 1 \\
\hline 1 Disagree \& 1 Neutral \& 1 Strongly Agree & 2 \\
\hline 2 Agree \& 1 Neutral & 2 \\
\hline 1 Disagree \& 1 Agree \& 1 Strongly Agree & 3 \\
\hline 2 Neutral \& 1 Strongly Agree & 3 \\
\hline 2 Strongly Agree \& 1 Strongly Disagree & 3 \\
\hline 3 Agree & 3 \\
\hline 1 Neutral \& 1 Agree \& 1 Strongly Agree & 4 \\
\hline 2 Agree \& 1 Strongly Agree & 5 \\
\hline 2 Strongly Agree \& 1 Disagree & 5 \\
\hline 2 Strongly Agree \& 1 Neutral & 6 \\
\hline 2 Strongly Agree \& 1 Agree & 7 \\
\hline 3 Strongly Agree & 9 \\
\hline
\end{tabular}

The numerical coding of the answers of the three items used to survey each of the fourteen determinants was added transforming each factor in a scale of three items. Then, the extreme value in both side of the answers' choices can be associated with a plus or minus sign pointing to the agree side or the disagree side, respectively. Table VI shows the scale score. 
$\begin{array}{lllllllllllllllll}-9 & -7 & -6 & -5 & -4 & -3 & -2 & -1 & 0 & 1 & 2 & 3 & 4 & 5 & 6 & 7 & 9\end{array}$

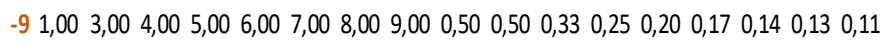

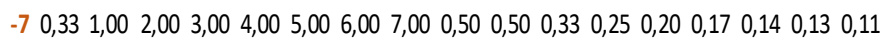

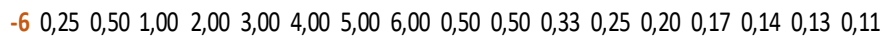

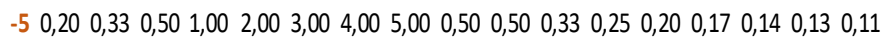

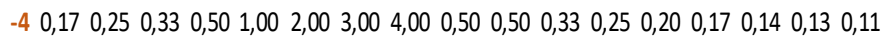

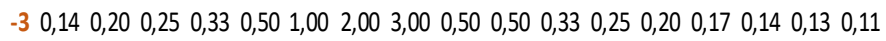

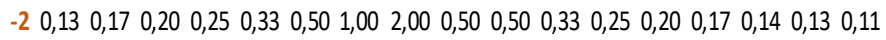

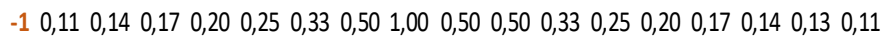

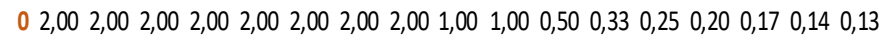

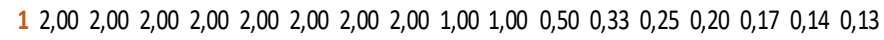
$23,003,003,003,003,003,003,003,002,002,001,000,500,330,250,200,170,14$ $\begin{array}{llllllllllllllllllllllll}34,00 & 4,00 & 4,00 & 4,00 & 4,00 & 4,00 & 4,00 & 4,00 & 3,00 & 3,00 & 2,00 & 1,00 & 0,50 & 0,33 & 0,25 & 0,20 & 0,17\end{array}$ $\begin{array}{llllllllllllllllllllllll}4,00 & 5,00 & 5,00 & 5,00 & 5,00 & 5,00 & 5,00 & 5,00 & 4,00 & 4,00 & 3,00 & 2,00 & 1,00 & 0,50 & 0,33 & 0,25 & 0,20\end{array}$ 5 6,00 6,00 6,00 6,00 6,00 6,00 6,00 6,00 5,00 5,00 4,00 3,00 2,00 1,00 0,50 0,33 0,25 $67,007,007,007,007,007,007,007,00$ 6,00 6,00 5,00 4,00 3,00 2,00 1,00 0,50 0,33

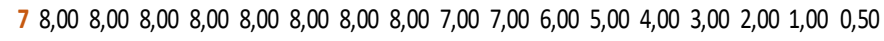
9 9,00 9,00 9,00 9,00 9,00 9,00 9,00 9,00 8,00 8,00 7,00 6,00 5,00 4,00 3,00 2,00 1,00

Fig. 4. Comparison Matrix for the New Absolute Scale.

TABLE VII. IDEALIZED PRIORITIES FROM SCALE SCORES

\begin{tabular}{|l|l|}
\hline Scale Score & Idealized Priority \\
\hline-9 & 0,1920 \\
\hline-7 & 0,1300 \\
\hline-6 & 0,1047 \\
\hline-5 & 0,0847 \\
\hline-4 & 0,0694 \\
\hline-3 & 0,0580 \\
\hline-2 & 0,0501 \\
\hline-1 & 0,0450 \\
\hline 0 & 0,1238 \\
\hline 1 & 0,1238 \\
\hline 2 & 0,1867 \\
\hline 3 & 0,2624 \\
\hline 4 & 0,3551 \\
\hline 5 & 0,4697 \\
\hline 6 & 0,6118 \\
\hline 7 & 0,7873 \\
\hline 9 & 1,0000 \\
\hline & \\
\hline
\end{tabular}

In order to get the priorities from the scale a decision matrix is built by means of researcher judgment about the relative classical AHP reciprocal measurement between the different scale scores as shows in Fig.4. The weights extracted from the matrix (Fig.4) as its principal right eigenvector using $\mathrm{R}$ software to calculate it. Then, idealized priorities were calculated by means of dividing each weight value by the biggest one. Table VII shows the idealized priorities obtained.

From the respondent ratings from each item, the scale values for each factor and each individual was determined by adding them, then change the scale value by the correspondent idealized priority using Table VII.
TABLE VIII. CONTRIBUTING WEIGHTS FOR ADOPTION FACTORS DERIVED FROM ALL INDIVIDUALS RESPONSES

\begin{tabular}{|c|c|c|c|c|}
\hline Criteria & $\begin{array}{l}\text { Criteria } \\
\text { Weight }\end{array}$ & Factors & $\begin{array}{l}\text { Weights } \\
\text { Regarding } \\
\text { Criteria }\end{array}$ & $\begin{array}{l}\text { Final Factor } \\
\text { Weight }\end{array}$ \\
\hline \multirow{4}{*}{$\begin{array}{l}\text { Perceived } \\
\text { Ease of Use }\end{array}$} & \multirow{4}{*}{0,487} & $\begin{array}{l}\text { Innovativen } \\
\text { ess }\end{array}$ & 0,289 & 0,1406 \\
\hline & & Optimism & 0,535 & 0,2603 \\
\hline & & Discomfort & 0,096 & 0,0468 \\
\hline & & Insecurity & 0,080 & 0,0389 \\
\hline \multirow{7}{*}{$\begin{array}{l}\text { Perceived } \\
\text { Usefulness }\end{array}$} & \multirow{7}{*}{0,513} & $\begin{array}{l}\text { Responsive } \\
\text { ness }\end{array}$ & 0,141 & 0,0725 \\
\hline & & Smartness & 0,144 & 0,0737 \\
\hline & & $\begin{array}{l}\text { Permanenc } \\
\mathrm{y}\end{array}$ & 0,144 & 0,0737 \\
\hline & & $\begin{array}{l}\text { Accessibilit } \\
\mathrm{y}\end{array}$ & 0,145 & 0,0746 \\
\hline & & Immediacy & 0,142 & 0,0729 \\
\hline & & $\begin{array}{l}\text { Interactivit } \\
\mathrm{y}\end{array}$ & 0,145 & 0,0744 \\
\hline & & $\begin{array}{l}\text { Context- } \\
\text { awareness }\end{array}$ & 0,140 & 0,0717 \\
\hline
\end{tabular}

In order to aggregate the 125 opinions about the eleven factors we use the geometric mean following [35] whose suggest the geometric mean as the unique suitable procedure for aggregate values expressed in ratio scales. Finally, the weights are the result of normalize those averages in any set of each criteria PEOU and PU respectively. This procedure was done again to get the relative weights of each criteria. The final weights are then calculated by multiplying weights of the factor by weight of the criteria associated with them. Final and intermediate weights are showed in Table VIII.

The main assumption using AHP is that each value judgment comes from an expert about the issue of concern. The sample that answered this research survey was not homogeneus on their expertise and knowledge, then it is reasonable to suppose that not all of them could provide equal responses in terms of informative value. All the respondents were consulted with three items adressing Intention to Adopt directly then it is possible to derive statistical measures about the predictive power of the model about intention to adopt using the final factor's weights obtained by using AHP and the survey answers to the intention to adopt. Both are very strength associated as its correlation coefficient shows $(\mathrm{r}=0.875)$.

It is also possible to determine the residuals from the predictions for each individual's Intention to Adopt in relation to their actual scale score for the same variable resulting in a maximum relative residual of $170,8 \%$ with a mean of $21,2 \%$. More than $80 \%$ of residuals are in the fewest residual classes. Applying the Pareto principle [36] is possible to make a second iteration in the AHP procedure excluding all 
individual's responses, which predicted intention to adopt relative residual is bigger than 36,0\%. 106 individuals remain in the reduced sample of more accurate individuals and their relative residual mean drops to $12,2 \%$. The resulting adjusted weights are presented in Table IX. The new correlation coefficient increases to $\mathrm{r}=0,982$ both measures validate predictive power of the adjusted weights of factors to evaluate the intention to adopt.

Based on results from AHP method, Table $\mathrm{X}$ shows the ranking of all adoption factors for U-Learning using NFC Technology.

TABLE IX. ADJUSTED WEIGHTS FOR ADOPTION FACTORS DERIVED FROM THE REDUCED SAMPLE OF MORE PRECISE INDIVIDUAL'S RESPONSES

\begin{tabular}{|c|c|c|c|c|}
\hline Criteria & $\begin{array}{l}\text { Criteria } \\
\text { Weight }\end{array}$ & Factors & $\begin{array}{l}\text { Weights } \\
\text { Regarding } \\
\text { Criteria }\end{array}$ & $\begin{array}{l}\text { Final Factors } \\
\text { Weight }\end{array}$ \\
\hline \multirow{4}{*}{$\begin{array}{l}\text { Perceived } \\
\text { Ease of Use }\end{array}$} & \multirow{4}{*}{0,503} & $\begin{array}{l}\text { Innovativen } \\
\text { ess }\end{array}$ & 0,307 & 0,1547 \\
\hline & & Optimism & 0,524 & 0,2637 \\
\hline & & Discomfort & 0,094 & 0,0473 \\
\hline & & Insecurity & 0,074 & 0,0374 \\
\hline \multirow{7}{*}{$\begin{array}{l}\text { Perceived } \\
\text { Usefulness }\end{array}$} & \multirow{7}{*}{0,497} & $\begin{array}{l}\text { Responsive } \\
\text { ness }\end{array}$ & 0,142 & 0,0705 \\
\hline & & Smartness & 0,145 & 0,0721 \\
\hline & & $\begin{array}{l}\text { Permanenc } \\
\mathrm{y}\end{array}$ & 0,142 & 0,0708 \\
\hline & & $\begin{array}{l}\text { Accessibilit } \\
\mathrm{y}\end{array}$ & 0,145 & 0,0721 \\
\hline & & Immediacy & 0,144 & 0,0714 \\
\hline & & $\begin{array}{l}\text { Interactivit } \\
\mathrm{y}\end{array}$ & 0,143 & 0,0709 \\
\hline & & $\begin{array}{l}\text { Context- } \\
\text { awareness }\end{array}$ & 0,139 & 0,0691 \\
\hline
\end{tabular}

TABLE X. RANKING OF ADOPTION FACTORS IN EDUCATION

\begin{tabular}{|l|l|l|}
\hline Ranking & Factors & Final Factors Weight \\
\hline 1 & Optimism & 0,2637 \\
\hline 2 & Innovativeness & 0,1547 \\
\hline $31 / 2$ & Accessibility & 0,0721 \\
\hline $31 / 2$ & Smartness & 0,0721 \\
\hline 5 & Immediacy & 0,0714 \\
\hline 6 & Interactivity & 0,0709 \\
\hline 7 & Permanency & 0,0708 \\
\hline 8 & Responsiveness & 0,0705 \\
\hline 9 & Context-awareness & 0,0691 \\
\hline 10 & Discomfort & 0,0473 \\
\hline 11 & Insecurity & 0,0374 \\
\hline
\end{tabular}

Results from AHP approach show that Optimism is the most important factor in adoption of U-Learning using NFC technology followed by Innovativeness. Factors of Accessibility and Smartness have the same final factors weight and the ranking shows the tie by half numbers, followed by Immediacy, Interactivity and Permanency, Responsiveness, Context-awareness, Discomfort, and Insecurity accordingly. Based on the findings, factors of TR have high impact in adopting sensor-based technology in education. It shows that users are optimistic and innovate with NFC technology utilization in education. Factor of Accessibility and Smartness also affected adoption of ULearning using NFC technology. Results from AHP approach illustrated that the characteristics of NFC-Enabled Ubiquitous Technology are important in the adoption of U-Learning using NFC technology. The results support that Accessibility as one of the factors which influence the adoption of U-Learning using NFC technology, which this research refer as an unsolved issue with current VLE.

\section{PROPOSED IMPLEMENTATION}

This paper proposed an NFC framework integrated with the conventional repository system such as Frog VLE based on literature review and key stakeholder's opinion analysis. The users are system administrators, teachers and students. The system administrator will be using the web application, whereas teachers and students will be using both web application and NFC application. There are three modules proposed which are administrator, teacher, and student module.

\section{A. Administrator Module}

System administrator of current Frog VLE enrolls students according to class application. Teachers will be assigned with particular subjects. Students Registration System administrator will register students' information into the system database. Teachers Registration-System administrator will register lecturers' information into the system database.

\section{B. Teacher Module}

1) Teaching material management: Teachers can upload the learning materials such as notes and exercises for the specific subjects into the system database. Teachers also enable to edit the content of learning materials. Access control is applied in this module to protect learning material from being edited by students.

2) Interactive learning management: Teachers can store learning materials from system database such as notes into NFC tags or NFC stickers and can attach the URL of the web application for specific subjects for additional information in NFC tag or sticker.

\section{Student Module}

1) Learning material management: Students can download the learning materials such as notes and exercises for specific subjects from the system database.

2) Interactive learning management: Students can access learning materials from NFC tag or NFC sticker and access 
the URL of the web application for specific subjects for additional information provided by teachers.

Fig.5 illustrates the use case diagram for NFC application development. The information from use case is useful for development phase of the System Development Life Cycle (SDLC).

Fig.6 illustrates the proposed NFC application framework which consists of System, Applications, Middleware, NFC Controller and NFC Features. The System layer consists of

VLE system, while Applications consist of modules from use case diagram. The middleware layer consists of two choices such as Open NFC and MORENA. The NFC Controller layer consists of NFC modes of operation and NFC Features layer consist of NFC devices.

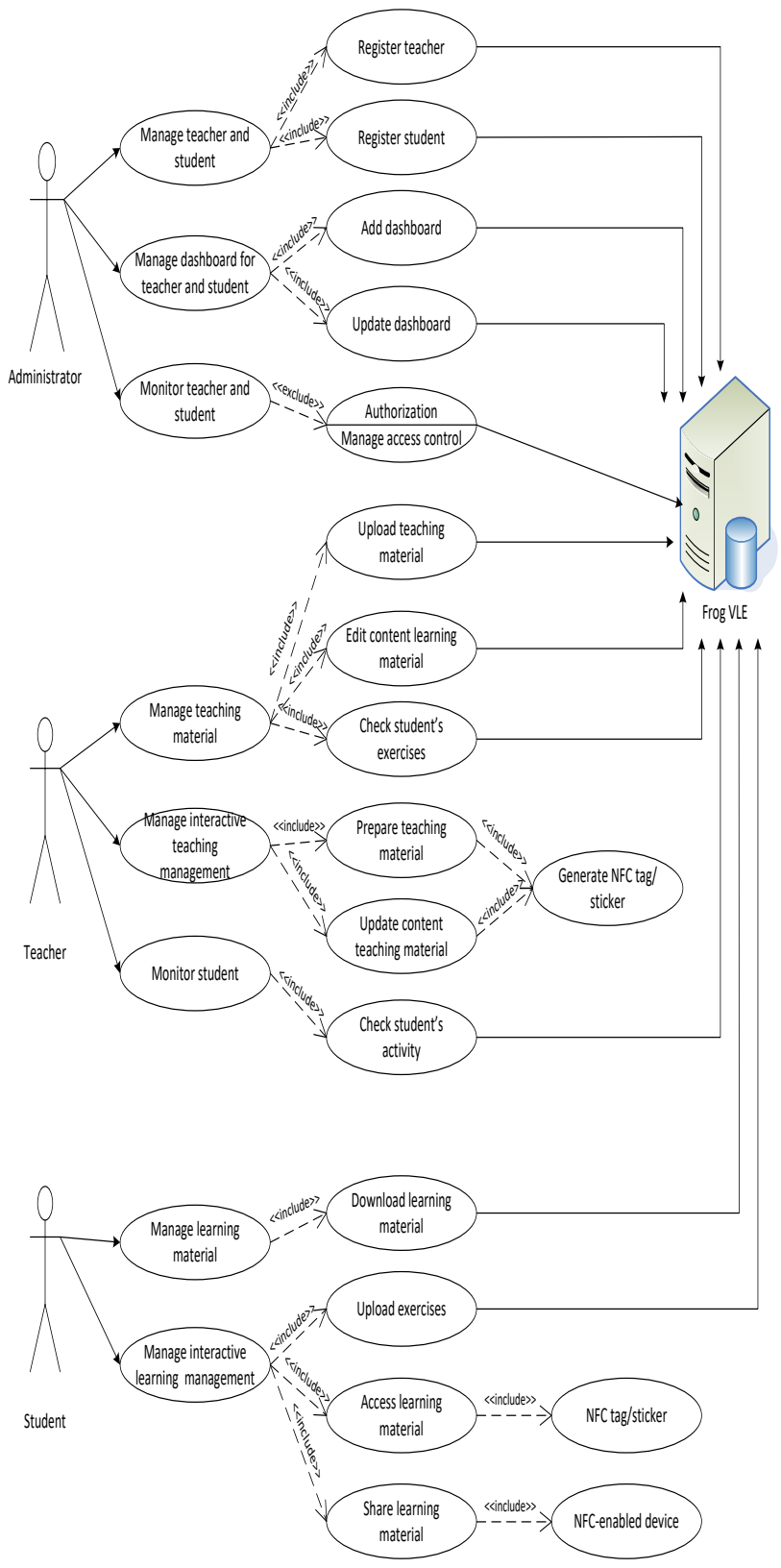

Fig. 5. Use Case Diagram for NFC System.

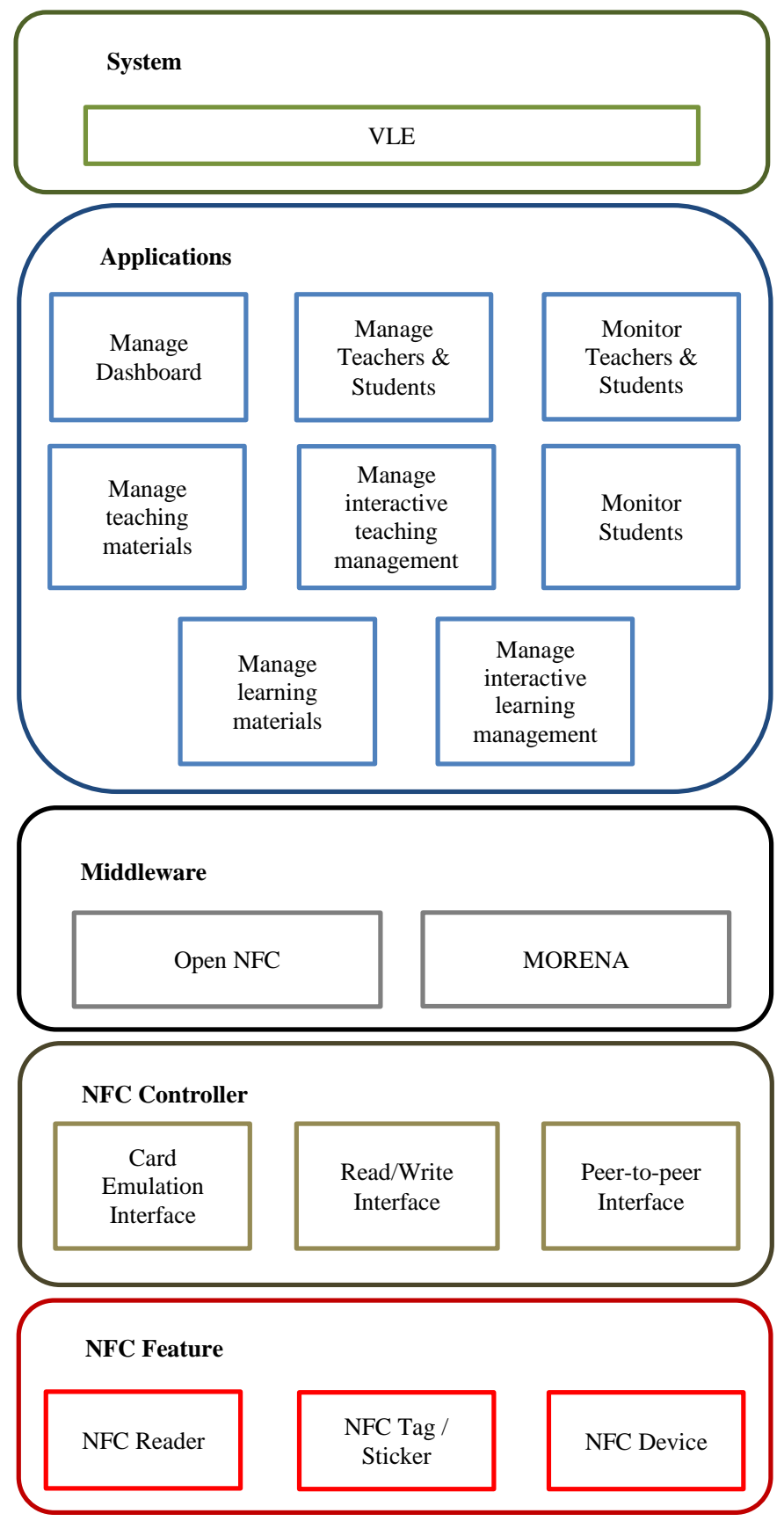

Fig. 6. Proposed NFC Application Framework.

Fig.7 illustrates the proposed NFC application framework for the NFC system using NFC application. It consists of various functions such as accessing, sharing, viewing and downloading learning materials. The web application is used for configuration of user's information, uploading and editing content of learning materials.

The factor of accessibility is an element in the research problem which motivated this research study. The idea of integrating current VLE system with NFC technology is suitable and appropriate to provide U-Learning concept for education sector. Therefore, the researcher has proposed VLE as centralized database and NFC application as framework through the NFC system integration framework. 


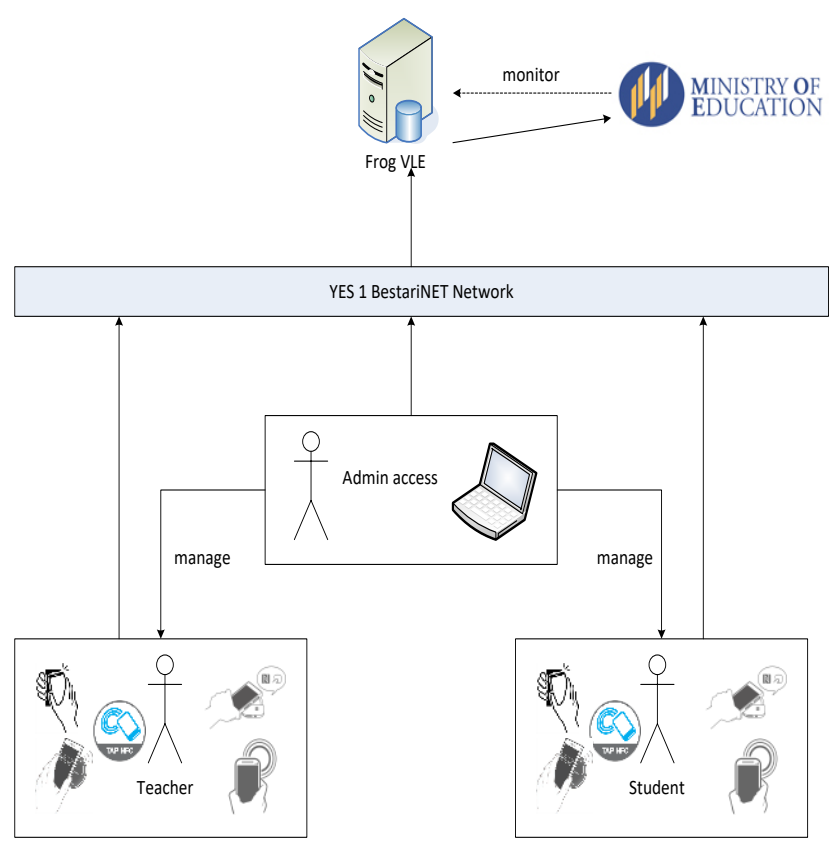

Fig. 7. Proposed NFC Application Architecture.

Based on findings from online survey, it can be claimed that accessibility of using NFC technology for U-Learning has positive impact on user's PU. The technology utilization will provide better solution in accessing current VLE and provide U-Learning environment simultaneously. The proposed NFC application framework will enhance the concept of ULearning and provide solution for current VLE systems.

\section{CONTRIBUTION AND DISCUSSION}

The research contributions are:

1) Design an NFC research model: The theoretical study regarding the U-Learning and NFC technology, which enables the researcher to propose NFC-Enabled Ubiquitous Technology Characteristics research model based on TRAM model. The proposed research model was used to analyze the adoption factors of U-Learning using NFC technology.

2) Ranking of adoption factors: The theoretical study about MCDM helps the researcher to rank adoption factors of U-Learning using NFC technology with AHP approach.

The factors of Optimism and Innovativeness have significant impact for U-Learning using NFC technology. Optimism and Innovativeness are constructs under TR. According to Parasuraman [28] Optimism is important when introducing new technology such as NFC technology. In this research, Optimism has the most impact factor by mean the respondents have positive view about using NFC technology in education. Innovativeness shows that respondents know that this factor allow them to shift from conventional to an advanced technique of teaching and learning. Innovativeness allows users to become pioneer with utilization of NFC technology in education [28].

Accessibility also provides significant impact on adoption of U-Learning using NFC based on survey and AHP results. This factor is one issue in current VLE implementation, whereby it only allows users to access VLE using specific devices such as laptop and tablet. Still, it needs users to key-in to access VLE in which becomes a constraint for users with disabilities such as visually impaired. According to [8] accessibility is one of U-Learning characteristics, which allow users more flexible access to information. By using NFC technology, it allows normal users and users with disabilities to access current VLE using NFC-enabled device with simple touch paradigm.

\section{CONCLUSION AND FUTURE WORK}

The evolution in education has transformed these processes from conventional technique to an advanced technique. It has been proven by the emergence of $\mathrm{E}$ Learning, M-Learning and U-Learning concepts in education. Advancement in computing technology has brought potential to utilize computing technology within teaching and learning. As a result, the NFC technology could provide benefits for both teachers and students.

This research results support the suggestion of implementation of NFC application for U-Learning in education based on the proposed framework in the future. The implementation will provide benefits for education enhancing the process of teaching and learning and achieving the target to provide education sector with 21 st century learning environment. This research shows some evidence about the implementation of the proposed framework could overcome constraints and challenges in current VLE.

The modular architecture in the proposed framework could be enhanced and further extended in the next phase of the implementation by including a module for people in administration, management of education institution and module to record attendance for students and academic staffs in future works. The research results advance the case for ULearning implementation in real educational system using NFC technology.

\section{REFERENCES}

[1] Ebner, M., \& Maierhuber, M. (2013). Near Field Communication-Which Potentials Does NFC Bring for Teaching and Learning Materials? International Journal of Interactive Mobile Technologies (iJIM), 7(4), 914.

[2] Zahrani, M. S. (2010). The benefits and potential of innovative ubiquitous learning environments to enhance higher education infrastructure and student experiences in Saudi Arabia. Journal of Applied Sciences(Faisalabad), 10(20), 2358-2368.

[3] Hoic-Bozic, N., Mornar, V., \& Boticki, I. (2009). A blended learning approach to course design and implementation. IEEE transactions on education, 52(1), 19-30.

[4] Chen, Y. S., Kao, T. C., Sheu, J. P., \& Chiang, C. Y. (2002). A mobile scaffolding-aid-based bird-watching learning system. In Wireless and Mobile Technologies in Education, 2002. Proceedings. IEEE International Workshop on (pp. 15-22). IEEE.

[5] Curtis, M., Luchini, K., Bobrowsky, W., Quintana, C., \& Soloway, E. (2002). Handheld use in K-12: A descriptive account. In Wireless and Mobile Technologies in Education, 2002. Proceedings. IEEE International Workshop on (pp. 23-30). IEEE.

[6] Ogata, H., \& Yano, Y. (2004). Context-aware support for computersupported ubiquitous learning. In Wireless and Mobile Technologies in Education, 2004. Proceedings. The 2nd IEEE International Workshop on (pp. 27-34). IEEE.

[7] Hwang, G. J., Chin-Chung, T., \& Yang, S. J. (2008). Criteria, strategies and research issues of context-aware ubiquitous learning. Journal of 
Educational Technology \& Society, 11(2).

[8] Yahya, S., Ahmad, E. A., \& Jalil, K. A. (2010). The definition and characteristics of ubiquitous learning: A discussion. International Journal of Education and Development using Information and Communication Technology, 6(1), 1.

[9] Tatar, D., Roschelle, J., Vahey, P., \& Penuel, W. R. (2003). Handhelds go to school: Lessons learned. Computer, (9), 30-37.

[10] Churchill, D., \& Churchill, N. (2008). Educational affordances of PDAs: A study of a teacher's exploration of this technology. Computers \& Education, 50(4), 1439-1450.

[11] Tsai, P. S., Tsai, C. C., \& Hwang, G. H. (2010). Elementary school students' attitudes and self-efficacy of using PDAs in a ubiquitous learning context. Australasian Journal of Educational Technology, 26(3).

[12] Xu, L., \& Yang, J. B. (2001). Introduction to multi-criteria decision making and the evidential reasoning approach (pp. 1-21). Manchester: Manchester School of Management.

[13] Saaty, T. L. (1977). A scaling method for priorities in hierarchival structures. Journal of Mathematical Psychology, 15(3), 234-281.

[14] Saaty, T. L. (1980). The Analytic Hierarchic Process. Nueva York: McGraw-Hill.Saaty, T. L. (1980). The analytic hierarchy process: planning, priority setting, resources allocation. New York: McGraw, 281.

[15] Saaty, T. L. (2006). Fundamentals of Decision Making and Priority Theory with The Analytic Hierarchy Process (2 ed.). Pittsburgh, PA, USA: RWS Publications.

[16] Aruldoss, M., Lakshmi, T. M., \& Venkatesan, V. P. (2013). A survey on multi criteria decision making methods and its applications. American Journal of Information Systems, 1(1), 31-43.

[17] Alonso, J. A., \& Lamata, M. T. (2006). Consistency in the analytic hierarchy process: a new approach. International journal of uncertainty, fuzziness and knowledge-based systems, 14(04), 445-459.

[18] Kumar, S., Luthra, S., Haleem, A., Mangla, S. K., \& Garg, D. (2015). Identification and evaluation of critical factors to technology transfer using AHP approach. International Strategic Management Review, 3(12), 24-42.

[19] Saaty, T. L. (2008). Decision making with the analytic hierarchy process. International journal of services sciences, 1(1), 83-98

[20] Vazquez-Briseno, M., Hirata, F. I., Sanchez-Lopez, J. D. D., JimenezGarcia, E., Navarro-Cota, C., \& Nieto-Hipolito, J. I. (2012). Using RFID/NFC and QR-code in mobile phones to link the physical and the digital world. Interactive Multimedia. Dr. Ioannis Deliyannis (Ed.) InTech, 219-242.

[21] Carreton, A. L., Pinte, K., \& De Meuter, W. (2012). MORENA: a middleware for programming NFC-enabled Android applications as distributed object-oriented programs. In Proceedings of the 13th International Middleware Conference (pp. 61-80). Springer-Verlag New
York, Inc.

[22] Park, S. Y. (2009). An analysis of the technology acceptance model in understanding university students' behavioral intention to use e-learning. Journal of Educational Technology \& Society, 12(3), 150.

[23] Bradley, J. (2009). The technology acceptance model and other user acceptance theories. In Handbook of research on contemporary theoretical models in information systems (pp. 277-294). IGI Global.

[24] Davis, F. D. (1989). Perceived usefulness, perceived ease of use, and user acceptance of information technology. MIS quarterly, 319-340.

[25] Legris, P., Ingham, J., \& Collerette, P. (2003). Why do people use information technology? A critical review of the technology acceptance model. Information \& management, 40(3), 191-204.

[26] Taylor, S., \& Todd, P. A. (1995). Understanding information technology usage: A test of competing models. Information systems research, 6(2), 144-176.

[27] Agarwal, R., \& Prasad, J. (1999). Are individual differences germane to the acceptance of new information technologies?. Decision sciences, 30(2), 361-391.

[28] Parasuraman, A. (2000). Technology Readiness Index (TRI) a multipleitem scale to measure readiness to embrace new technologies. Journal of service research, 2(4), 307-320.

[29] Matthing, J., Kristensson, P., Gustafsson, A., \& Parasuraman, A. (2006). Developing successful technology-based services: the issue of identifying and involving innovative users. Journal of Services Marketing, 20(5), 288-297.

[30] Lin, C. H., Shih, H. Y., \& Sher, P. J. (2007). Integrating technology readiness into technology acceptance: The TRAM model. Psychology \& Marketing, 24(7), 641-657.

[31] Rossiter, J. R. (2010). Measurement for the social sciences: The COAR-SE method and why it must replace psychometrics. Springer Science \& Business Media

[32] Saaty, T. L. (2016). The analytic hierarchy and analytic network processes for the measurement of intangible criteria and for decisionmaking. In Multiple Criteria Decision Analysis(pp. 363-419). Springer, New York, NY.

[33] Brunelli, M. (2015). Introduction and Fundamentals. In Introduction to the Analytic Hierarchy Process (pp. 1-15). Springer, Cham.

[34] Saaty, T. L. (1986). Absolute and relative measurement with the AHP. The most livable cities in the United States. Socio-Economic Planning Sciences, 20(6), 327-331.

[35] Aczél, J., \& Saaty, T. L. (1983). Procedures for synthesizing ratio judgments. Journal of Mathematical Psychology, 27(1), 93-102. doi:10.1016/0022-2496(83)90028-7.

[36] Koch, R. (1998). The 80/20 Principle: The Secret of Achieving More with Less, Bantam Doubleday. 